\title{
Avaliação das Proporções dos Cortes da Carcaça, Características da Carne e Avaliação dos Componentes do Peso Vivo de Cordeiros ${ }^{1}$
}

\author{
Rafael Batista Medeiros Frescura ${ }^{2}$, Cleber Cassol Pires ${ }^{3}$, José Henrique Souza da Silva ${ }^{4}$, \\ Liziany Müller ${ }^{5}$, Adriano Cardoso $0^{5}$, Carlos Júnior Kippert ${ }^{5}$, Diego Peres Neto $^{5}$, Cláudia Dutra \\ da Silveira ${ }^{5}$, Leandro Alebrante ${ }^{5}$, Leonardo Thomas $^{5}$
}

\begin{abstract}
RESUMO - Objetivou-se, neste trabalho, avaliar a composição física da carcaça, as características da carne e a proporção dos nãocomponentes da carcaça do peso vivo de cordeiros abatidos aos $28 \mathrm{~kg}$ submetidos a diferentes sistemas alimentares. Dezoito cordeiros (Ile de France x Texel ) foram distribuídos aleatoriamente, com as respectivas mães, em três tratamentos: PCA - pastagem cultivada de azevém (Lolium multiflorum Lam.), CON - confinamento sem alimentação privativa e CCF - confinamento com alimentação privativa para os cordeiros. A alimentação privativa foi oferecida aos cordeiros pelo sistema de creep feeding. Não houve diferença para o percentual do pescoço entre PCA, CON e CCF, com valores de 9,27; 9, 17 e 8,72\%, respectivamente. Para o percentual de perna, os animais da CON $(34,02 \%)$ e CCF $(34,17 \%)$ apresentaram valores semelhantes entre si e superiores aos da PCA $(31,73 \%)$. A maciez medida na porção do Longissimus dorsi entre a $9^{\mathrm{a}}$ e $12^{\mathrm{a}}$ costelas foi semelhante entre os animais dos três tratamentos, de 2,33; 3,03 e 3,08 para PCA, CON e CCF, respectivamente. Não houve efeito dos tratamentos sobre a palatabilidade e suculência da carne. O percentual de pele dos animais da PCA $(11,05 \%)$ e do CON (10,50\%) foram semelhantes entre si, enquanto o PCA apresentou valores mais elevados que o percentual dos animais do CCF (9,70\%). Para o percentual do conteúdo gástrico, os valores observados para os animais do CCF (11,47\%) foram superiores àqueles da PCA $(5,09 \%)$ e semelhantes aos obtidos para os animais do CON $(8,72 \%)$.
\end{abstract}

Palavras-chave: confinamento, pastagem de azevém, maciez, palatabilidade, suculência

\section{Evaluation of Carcass Cuttings Proportion, Meat Characteristics and Evaluation of Live Weight Components of Lambs}

\begin{abstract}
This study aimed to evaluate carcass physical comp0sition, meat characteristics and live weight carcass no component of lambs slaughter at $28 \mathrm{~kg}$ under different feeding systems. Eighteen lambs (Ile de France X Texel) were randomly allotted, with their respective mothers, to three treatments: RP - ryegrass pasture (Lolium multiflorum Lam.), COM - confinament of lamb and sheep together and CCF - confinament with creep feeding. A private feeding by creep feeding system was offered for the lambs. There were no difference in the neck percentage among RP, COM and CCf, with values of 9.27, 9.17, and 8.72\%, respectively. In relation to the legs, COM (34.02\%) and CCF (34.17\%) animals expressed similar values and were superior than $\mathrm{RP}(31.73)$ animals values. The softness measured in the loin portion (Longissimus dorsi), from $9^{\text {th }}$ to $12^{\text {th }}$ rib was the same in the animals submitted to three treatments: RP, COM and CCF, with respective values of 2.33, 3.03 and 3.08. There were not effects in the treatments according to juiceness (SUC) and taste (TASTE). The skin percentage of RP (11.05\%) and COM (10.50\%) were no treatment effects to the through the panel, palatability and juiceness. The skin percentages of RP (11.05\%) and CON (10.50\%) animals were similar, and RP showed higher values than CCF $(9.70 \%)$. The values of gastric content percentage for CCF $(11.47 \%)$ animals were higher than the RP animals (5.09\%) and showed similar value for CON $(8.72 \%)$.
\end{abstract}

Key Words: confinement, ryegrass pasture, softness, tastiness, juiciness

\section{Introdução}

No processo de produção de carne ovina, o abate de cordeiros jovens permite a obtenção de carcaças com pouca deposição de gordura e carne macia aspectos importantes para conquistar consumidores que exigem qualidade dos produtos. Segundo Ávila (1995), a qualidade de uma carcaça não depende apenas do peso, mas também do teor de gordura, da composição muscular, da conformação, da idade dos animais e da características organolépticas da carne. De acordo com Fagundes Neto et al. (2002) e Silva

\footnotetext{
1 Parte da Dissertação de Mestrado do primeiro autor.

2 Zootecnista, M.Sc. Bolsista CAPES (rfrescura@bol.com.br).

${ }_{3}$ Med. Vet., Dr., Professor Titular DZ-UFSM, CEP: 97105-900, Santa Maria, RS (cpires@.ccr.ufsm.br).

4 Eng. Agr., Phd., Professor Adjunto DZ- UFSM, Santa Maria, RS.

${ }^{5}$ Aluno de graduação em Zootecnia.
} 
Sobrinho et al. (1996), o sabor, a maciez, o odor e a quantidade de gordura são preferenciais e podem serem afetados pelo sistema de alimentação dos animais.

A divisão da carcaça nos cortes pescoço, costilhar, paleta e perna permite melhor utilização na culinária e facilita a comercialização e, de acordo com Sainz (1996), o rendimento dos cortes da carcaça é indicativo de qualidade.

Osório et al. (1997) observaram que a paleta e a perna são as peças mais importantes da carcaça, pois são cortes nobres e, por conseguinte, de maior valor comercial.

Além da carcaça, outros componentes (sistema digestivo e seu conteúdo, pele, cabeça, patas, pulmões com traquéia, fígado, coração, rins, baço gordura interna e pélvica, testículos e cauda) do peso vivo podem ser comercializados e, assim, agregar valor ao animal em geral (Gastaldi et al., 2000). Esses autores comentam que estes componentes do peso vivo animal podem representar até $40 \%$ do peso vivo dos ovinos, sendo influenciados pela genética, pela idade, pelo peso vivo, pelo sexo, pelo tipo de nascimento e, sobretudo, pela alimentação.

Siqueira et al. (2001) constataram que a pele e o conteúdo gastrintestinal são fatores determinantes sobre o rendimento da carcaça, pois ambos podem representar cerca de $25 \%$ do peso vivo ao abate. A contribuição da pele decorre de diferentes densidades, diâmetros das fibras e altura das mechas e do conteúdo gastrintestinal pelos distintos alimentos, com velocidades de passagem variáveis e períodos de jejum sem padronização.

Neste estudo, as proporções dos cortes da carcaça, características da carne e os componentes do peso vivo de cordeiros terminados em pastagem cultivada de azevém (Lolium multiflorum Lam.) e em confinamento foram avaliados.

\section{Material e Métodos}

O experimento foi conduzido no Departamento de Zootecnia da Universidade Federal de Santa Maria (UFSM), situada na Depressão Central do Rio Grande do Sul, com altitude de 95 metros, latitude 29 $9^{\circ} 403^{\prime}$ Sul e longitude 53² $2^{\prime}$ Oeste (Moreno, 1961). O solo pertence à unidade de mapeamento São Pedro, classificado como Podzólico Vermelho Amarelo Distrófico, que se caracteriza por ser profundo, avermelhado, com textura superficial arenosa (BRASIL, 1973).

\footnotetext{
R. Bras. Zootec., v.34, n.1, p.167-174, 2005
}

O período experimental correspondeu aos meses de julho a novembro de 2001. De acordo com dados da Estação Meteorológica de Santa Maria, nesse período as médias mensais foram: temperatura de $17,4^{\circ} \mathrm{C}$, umidade relativa do ar de $78,75 \%$, precipitação pluviométrica de $168,07 \mathrm{~mm}^{3}$ e precipitação total de $672,3 \mathrm{~mm}^{3}$.

Dezoito cordeiros não-castrados, cruza Ile de France x Texel, de partos simples, foram distribuídos aleatoriamente, com suas respectivas mães, nos tratamentos: PCA - pastagem cultivada de azevém (Lolium multiflorum Lam); CON - confinamento sem alimentação privativa para os cordeiros e CCF confinamento com alimentação privativa aos cordeiros. A alimentação privativa foi oferecida aos cordeiros pelo sistema de creep feeding.

Em todos os tratamentos, os cordeiros e suas mães permaneceram juntos até o abate, constituindo a unidade ovina (ovelha + cordeiro).

A área total (1,07 ha) da pastagem cultivada de azevém (Lolium multiflorum Lam.) foi subdividida em duas áreas menores. O estabelecimento da pastagem ocorreu no dia quatro de maio, com $50 \mathrm{~kg} / \mathrm{ha}$ de semente de azevém, adubação de $200 \mathrm{~kg} / \mathrm{ha}$ de NPK (05-20-20) e adubação nitrogenada de 157,70 kg/ha de nitrogênio, dividida em quatro aplicações.

As avaliações da massa de forragem da pastagem cultivada foram realizadas pelo método de dupla amostragem (Gardner, 1986), a cada 21 dias. A massa de forragem pretendida era de 1.000 a $1.200 \mathrm{~kg}$ de MS/ha.

No dia correspondente a metade do intervalo das duas avaliações foi coletada, por dois avaliadores, a forragem aparentemente consumida pelos animais pela técnica de simulação de pastejo (Gibb \& Treacher, 1976).

O sistema de pastejo utilizado foi o contínuo com lotação variável. A taxa de acúmulo de matéria seca foi obtida utilizando gaiolas de exclusão e para o cálculo da taxa de acúmulo diário foi utilizada a equação descrita por Campbell (1966).

A oferta de forragem foi determinada por meio da divisão da massa de forragem existente na entrada dos animais no piquete, somada à taxa de acúmulo prevista para o período pela carga animal no período de utilização e expressa em kg de MS/100 kg de PV. As perdas de forragem foram avaliadas a cada 21 dias, sendo marcados 15 pontos com estacas, quando as amostras de material senescente, morto e danificado pelo pisoteio e pastejo foram coletadas, em cada ponto, com auxílio de um quadrado de $0,1 \mathrm{~m}^{2}$. Após cada coleta, as amostras foram secas em estufa e pesadas para cálculo da perda de forragem por hectare. 
Para o cálculo do consumo estimado de MS, foram subtraídas da produção total de MS/ha (massa de forragem inicial + taxa de acúmulo diário * número de dias) a forragem disponível no final do período experimental e as perdas de forragem ocorridas ao longo do período de pastejo. Dividindo o consumo estimado de MS/ha pela carga animal média, obteve-se o consumo estimado de MS em \% do PV. O período de utilização da pastagem foi de 09/07 a 1/11/2001.

Nos confinamentos a céu aberto, foram usados piso de terra coberto com casca de arroz e uma área (10 $\mathrm{m}^{2} /$ ovelha+cordeiro) onde a silagem de sorgo, cultivar Agroceres 2002 (AG 2002), e o concentrado foram fornecidos à vontade, às $8 \mathrm{~h}$ e $16 \mathrm{~h}$. A quantidade oferecida foi ajustada diariamente, com aumento ou redução de $10 \%$, conforme a sobra do dia anterior, que deveria ser de até $20 \%$ da quantidade oferecida. Cada tratamento tinha sal mineralizado com livre acesso para os animais. No confinamento sem alimentação privativa para os cordeiros $(\mathrm{CON})$, o alimento fornecido foi de $50 \%$ de volumoso e $50 \%$ de concentrado (Ovino Criador, Santista Alimentos). Cada animal consumiu $11,34 \%$ de PB e $64,28 \%$ de NDT da dieta $(11,5 \%$ de PB e $64,40 \%$ de NDT) oferecida neste tratamento.

No confinamento com alimentação privativa (CCF), foi fornecida dieta com $75 \%$ de volumoso e $25 \%$ de concentrado, contendo $8,20 \%$ de $\mathrm{PB}$ e $60,60 \%$ de NDT. Cada animal consumiu $7,80 \%$ de PB e $60,48 \%$ de NDT da dieta ofertada neste tratamento.

Quando os cordeiros atingiram 21 dias no tratamento começaram a receber o concentrado (18,12\% de PB e $72,01 \%$ de NDT), em quantidade de $3 \%$ do peso vivo. O consumo durante três períodos de 21 dias foi, em média, de 1,90\% do PV.

Os animais foram everminados com antihelmíntico para o controle de endoparasitos no início do experimento e a cada 30 dias.

Ovelhas e cordeiros foram pesados no início do experimento e a cada 21 dias, com jejum prévio de sólidos e líquidos (14 horas). Foram coletadas diáriamente amostras diárias dos alimentos oferecidos e das sobras dos animais em confinamento para posteriores análises laboratoriais.

Os teores de matéria seca e matéria orgânica, proteína bruta, extrato etéreo, fibra bruta, extrativos não-nitrogenados e cinzas foram determinados pelo método AOAC (1984), digestibilidade in vitro da matéria orgânica e da matéria seca (Tilley \& Terry, 1963).
O cálculo para se obter concentração de NDT foi realizado segundo Freitas et al. (1994):

$$
\mathrm{MO}=100-\mathrm{MM}
$$

em que: $\mathrm{MO}=$ matéria orgânica; $\mathrm{MM}=$ matéria mineral.

$$
\% \mathrm{NDT}=(\mathrm{MOxDIVMO}) / 100
$$

em que DIVMO= digestibilidade in vitro da matéria orgânica.

$\mathrm{O}$ abate dos animais ocorreu quando atingiram o peso de $28 \mathrm{~kg}$ (peso de fazenda). Após o abate, cabeça, patas, pele, sangue, pulmão + traquéia, coração e fígado foram pesados. O trato gastrintestinal foi pesado cheio e vazio e, assim, obtido o conteúdo gástrico e intestinal. Na seqüência, estas vísceras foram lavadas e pesadas novamente para obtenção do peso vazio do rúmen e retículo, omaso e abomaso. A carcaça foi resfriada por 24 horas, a $2^{\circ} \mathrm{C}$, e na metade esquerda foi realizada a separação regional dos devidos cortes (pescoço, paleta, costelas e perna). Para análise da carne, foi retirada a porção do lombo correspondente ao intervalo da $9^{\mathrm{a}}$ à $12^{\mathrm{a}}$ costelas após congelamento por, no mínimo, 15 dias. Nesta porção foram cortados dois bifes de cada amostra, com 2,5 cm de espessura. Após descongelamento a $5^{\circ} \mathrm{C}$ por 24 horas, foram assados a uma temperatura interna de $70^{\circ} \mathrm{C}$, durante 15 minutos. Um bife de cada amostra foi cortado ainda quente, em cubos de $2 \mathrm{~cm}^{3}$, e distribuídos ao acaso para um "painel" composto por cinco degustadores, que avaliaram subjetivamente a maciez, suculência e palatabilidade da carne, atribuindo valores de 1 (extremamente dura, sem suculência e sem palatabilidade) a 9 (extremamente macia, extremamente suculenta e extremamente palatável).

$\mathrm{O}$ segundo bife permaneceu à temperatura ambiente, retirando-se três amostras de 1,25 cm de diâmetro paralelas à direção das fibras musculares, para determinação da força de cisalhamento no aparelho Warner Bratzler-Shear. Esta metodologia de avaliação utilizada foi segundo Müller (1980).

Para análise estatística dos dados, foi empregado o delineamento experimental inteiramente casualizado com três tratamentos. A metodologia estatística incluiu análise de variância e teste F. Diferenças significativas a $5 \%$ ensejaram aplicação do teste Tukey neste mesmo nível de significância. As análises foram realizadas por intermédio do SAS (1993). 


\section{Resultados e Discussão}

Os valores percentuais do pescoço, da paleta, da costela e da perna são apresentados na Tabela 1.

Osório et al. (2002), avaliando cordeiros oriundos cruza Border Leicester com ovelhas Ideal e Corriedale, não-castrados, desmamados aos 45 dias em condições extensivas de campo natural, com lotação de 0,5 unidade animal por hectare com peso de abate ao redor de $32 \mathrm{~kg}$, verificaram valores de $9,07 \%$ para o pescoço e de $19,96 \%$ para a paleta. Esses valores são próximos ao do presente estudo, embora os cordeiros fossem $4 \mathrm{~kg}$ mais leves ao abate.

A proximidade dos resultados deve-se à boa condição alimentar dos cordeiros do presente estudo, que permitiu maior desenvolvimento dos cortes com menor peso de abate. Apesar de os animais do experimento apresentarem peso de abate e carcaça semelhantes, observa-se maior porcentagem de costelas dos animais da pastagem cultivada em relação aos demais, o que ocasionou menor porcentagem de perna das carcaças dos animais do tratamento PCA. Portanto, a maior porcentagem de costelas está relacionada à maior deposição de gordura.

Tonetto et al. (2004) não verificou efeito das diferentes dietas sobre os rendimentos de pescoço e paleta, mas, para rendimento de costelas, os cordeiros cruza Ile de France sob pastagem cultivada de azevém $(40,68 \%)$ foram superiores $(\mathrm{P}<0,05)$ aos animais sob pastagem natural suplementada e confinamento (39,02 e 37,61\% respectivamente).
Esse autor observou, que para a perna, os animais sob pastagem cultivada obtiveram rendimento inferior, diferindo significativamente $(\mathrm{P}<0,05)$ dos animais sob pastagem natural suplementada e confinamento. A deposição de gordura na carcaça ocorre de forma rápida pelo lombo e costilhar, depois o crescimento é lento intermuscular e pela região da paleta (Kempster et al., 1987). De acordo com Roque et al. (1998), o aumento de rendimento de costela não é desejado, pois o valor comercial é inferior aos dos outros cortes. Monteiro (1998) citou que, entre os cortes, a perna é a mais nobre em carcaças ovinas. Carvalho et al. (1999) não encontraram diferenças $(\mathrm{P}>0,05)$ para rendimentos de perna $(32,23 \%)$, de paleta $(19,64 \%)$ e de costelas $(26,86 \%)$, trabalhando com cordeiros cruza Texel x raças laneiras alimentados ao pé da mãe em pastagem cultivada de azevém + aveia + trevo vesciculoso e silagem mais concentrado, abatidos aos $30 \mathrm{~kg}$. Carneiro (2001), ao confinar cordeiros cruza Texel não-castrados de parto simples ao pé da mãe e cordeiros desmamados aos 63 dias abatidos aos $30 \mathrm{~kg}$, não encontrou diferenças $(\mathrm{P}>0,05)$ para os rendimentos de paleta, costelas e perna com valores médios de 19,$50 ; 38,41$ e $33,77 \%$, respectivamente, valores semelhantes aos do presente estudo.

Os resultados referentes às características organolépticas da carne dos cordeiros nos três sistemas de alimentação são apresentados na Tabela 2.

A ausência de efeito das diferentes formas de alimentações no experimento com relação à maciez da carne pode ser atribuída à semelhança da idade

Tabela 1 - Rendimentos de pescoço (PES), paleta (PAL), costela (COS) e perna (PER), nos tratamentos pastagem cultivada de azevém (PCA), confinamento sem alimentação privativa (CON) e confinamento com alimentação privativa (CCF), coeficiente de variação $(C V)$, valor de $F(F)$ e probabilidade $(P r>F)$

Table 1 - Neck (NEC), shoulder (SHO), rib (RIB) and leg yields in the treatments, ryegrass pasture (RP), confinement (CON) confinement with creep feeding (CCF), coefficient of variation $(C V), F$ value $(F)$ and probability $(\operatorname{Pr}>F)$

\begin{tabular}{|c|c|c|c|c|c|c|}
\hline \multirow[t]{2}{*}{$\begin{array}{l}\text { Variáveis } \\
\text { Variables }\end{array}$} & \multicolumn{3}{|c|}{$\begin{array}{c}\text { Tratamentos } \\
\text { Treatments }\end{array}$} & \multirow[t]{2}{*}{ CV } & \multirow[t]{2}{*}{$\mathrm{F}$} & \multirow[t]{2}{*}{$\operatorname{Pr}>F$} \\
\hline & $\begin{array}{c}\text { PCA } \\
R P\end{array}$ & $\begin{array}{l}\mathrm{CON} \\
\mathrm{CON}\end{array}$ & $\begin{array}{l}\mathrm{CCF} \\
C C F\end{array}$ & & & \\
\hline $\begin{array}{l}\text { PES (\%) } \\
N E C(\%)\end{array}$ & 9,27 & 9,17 & 8,72 & 7,88 & 0,99 & 0,3937 \\
\hline $\begin{array}{l}\text { PAL (\%) } \\
\text { SHO(\%) }\end{array}$ & 18,68 & 19,52 & 19,31 & 3,57 & 2,43 & 0,1217 \\
\hline $\begin{array}{l}\operatorname{COS}(\%) \\
R I B(\%)\end{array}$ & $39,60^{\mathrm{a}}$ & $37,34^{b}$ & $37,72^{\mathrm{ab}}$ & 3,43 & 5,08 & 0,0206 \\
\hline $\begin{array}{l}\text { PER (\%) } \\
L E G(\%)\end{array}$ & $31,73^{b}$ & $34,02^{\mathrm{a}}$ & $34,17^{\mathrm{a}}$ & 2,81 & 12,75 & 0,0006 \\
\hline
\end{tabular}

Médias seguidas de letras diferentes na linha diferiram $(P<0,05)$ pelo teste Tukey.

Averages followed by different letters in line differ $(P<.05)$ by Tukey test.

\section{R. Bras. Zootec., v.34, n.1, p.167-174, 2005}


Tabela 2 - Valores médios para as características qualitativas da carne de cordeiros (maciez no painel [MAC-PAI], maciez-Shear [MAC-SHI], palatabilidade [PALA] e suculência [SUC]), de acordo com o tratamentos (pastagem cultivada de azevém - PCA, confinamento sem alimentação privativa - CON e confinamento com alimentação privativa - CCF), coeficiente de variação $(\mathrm{CV})$, valor de $\mathrm{F}(\mathrm{F})$ e probabilidade $(\mathrm{Pr}>\mathrm{F})$

Table 2 - Average values obtained for the meat qualitative characteristics of lambs (softness - test panel [SOF-PAN],softness-Shear [SOF-SHI], palatability [PALATA] and juiceness [SUC]), according to the treatments (ryegrass pasture - RP, confinement - CON and confinement with creep feeding - CCF), coefficient of variation $(C C), F$ value $(F)$ and probability $(P r>F)$

\begin{tabular}{|c|c|c|c|c|c|c|}
\hline \multirow[t]{2}{*}{$\begin{array}{l}\text { Variável } \\
\text { Variable }\end{array}$} & \multicolumn{3}{|c|}{$\begin{array}{c}\text { Tratamentos } \\
\text { Treatments }\end{array}$} & \multirow[t]{2}{*}{$\mathrm{CV}$} & \multirow[t]{2}{*}{$\mathrm{F}$} & \multirow[t]{2}{*}{$\operatorname{Pr}>\mathrm{F}$} \\
\hline & $\begin{array}{c}\text { PCA } \\
R P \\
\end{array}$ & $\begin{array}{l}\mathrm{CON} \\
\mathrm{CON}\end{array}$ & $\begin{array}{l}\mathrm{CCF} \\
C C F\end{array}$ & & & \\
\hline $\begin{array}{l}\text { MAC-PAI } \\
\text { SOF-PAN }\end{array}$ & 7,75 & 7,37 & 7,29 & 12,93 & 0,38 & 0,6885 \\
\hline $\begin{array}{l}\text { MAC-SHI } \\
\text { SOF-SHI }\end{array}$ & 2,33 & 3,03 & 3,08 & 61,68 & 0,35 & 0,7104 \\
\hline $\begin{array}{l}\text { PALA } \\
\text { PALATA }\end{array}$ & 6,66 & 6,16 & 6,91 & 10,74 & 1,75 & 0,2074 \\
\hline $\begin{array}{l}\text { SUC } \\
\text { SUC }\end{array}$ & 6,82 & 6,65 & 7,01 & 11,73 & 0,32 & 0,6352 \\
\hline
\end{tabular}

Médias seguidas de letras diferentes na linha diferem $(P<0,05)$ pelo teste Tukey.

Averages followed by different letters in line differ $(P<.05)$ by Tukey test.

dos cordeiros ao abate, de 70, 65 e 74 dias para os tratamentos PCA, CON e CCF, respectivamente. Tonetto et al. (2004), estudando cordeiros cruza Ile de France $\mathrm{x}$ Texel criados ao pé da mãe em pastagem natural com creep feeding, pastagem de azevém e confinamento com creep feeding, abatidos aos 75 , 62 e 98 dias, respectivamente, com, em média, $31 \mathrm{~kg}$, não encontrou diferença $(\mathrm{P}>0,05)$ entre os tratamentos para maciez, palatabilidade e suculência, com valores médios de 7,$32 ; 6,73$ e 6,72 , respectivamente. A média de 6,50 obtida nesse trabalho para maciez no aparelho Warner Bratzler-Shear foi superior à citada na Tabela 2. Monteiro (1998), trabalhando com cordeiros em pastagem natural melhorada, com lotação de 20-25 animais/ha e abatidos aos 150 dias, observou que a força de cisalhamento no aparelho Warner Bratzler-Shear para os cordeiros Corriedale e cruzas Ile de France (F1) foi de 3,04 e 3,65, respectivamente, valores aproximados ao presente estudo.

Os pesos dos componentes do peso vivo e os valores percentuais, em função do peso vivo de abate nos diferentes tratamentos, são apresentados nas Tabelas 3 e 4, respectivamente.

Siqueira et al. (2001), ao confinarem cordeiros cruza Ile de France x Corriedale, não castrados de parto simples, desmamados aos 60 dias com $12 \mathrm{~kg}$ e abatidos aos $28 \mathrm{~kg}$ de peso vivo, obtiveram valores para peso de cabeça e patas de 1,65 e $0,65 \mathrm{~kg}$, respectivamente. $\mathrm{O}$ valor de peso de cabeça foi

R. Bras. Zootec., v.34, n.1, p.167-174, 2005 superior ao do presente experimento, embora o peso das patas tenha mostrado semelhança.

Os cordeiros do PCA e CON apresentaram semelhança para peso e percentual da pele, enquanto os do PCA foram superiores $(\mathrm{P}<0,05)$ aos animais do CCF. Müller et al. (2002) encontraram superioridade $(\mathrm{P}<0,05)$ para valores relativo e absoluto da pele de cordeiros alimentados ao pé da mãe, em pastagem cultivada de azevém, em relação aos animais sob pastagem natural suplementada e confinamento. Siqueira et al. (2001) encontraram valor médio de 2,95 kg para pele de cordeiros cruza Ile de France x Corriedale, confinados e abatidos aos $28 \mathrm{~kg}$, valor esse aproximado ao do presente experimento.

Os valores de sangue, pulmão + traquéia, coração, fígado e rins não diferiram $(\mathrm{P}>0.05)$, em razão de os pesos ao abate dos cordeiros serem semelhantes. Os percentuais rúmen + retículo (vazio), omaso (vazio) e conteúdo intestinal não diferiram entre os tratamentos. Osório et al. (1997), ao compararem as vísceras verdes entre raças, citam que o Texel, seguido do Romney Marsh, apresentaram maiores valores absolutos que os ovinos das raças Merino e Ideal, o que se deve ao fato de os animais de porte maior (Texel e Romney Marsh) apresentarem maior necessidade nutricional e, conseqüentemente, maiores consumo e desenvolvimento das vísceras verdes que os animais de raças menores.

Nos animais do tratamento $\mathrm{CCF}$, foi verificado maior conteúdo gástrico $(\mathrm{P}<0,05)$ em relação aos da 
Tabela 3 - Valores médios dos componentes do peso vivo $(\mathrm{kg})$ nos tratamentos (pastagem cultivada de azevém - PCA, confinamento sem alimentação privativa - CON e confinamento com alimentação privativa - CCF), coeficiente de variação $(\mathrm{CV})$, valor de $\mathrm{F}(\mathrm{F})$ e probabilidade $(\mathrm{Pr}>\mathrm{F})$

Table 3 - Average values of live weight components $(\mathrm{kg})$ in the treatments (ryegrass pasture - RP, confinement - CON and confinement with creep feeding - CCF), coefficient of variation $(C V), F$ value $(F)$ and probability $(P r>F)$

\begin{tabular}{|c|c|c|c|c|c|c|}
\hline \multirow[t]{2}{*}{$\begin{array}{l}\text { Componentes do peso vivo }(\mathrm{kg}) \\
\text { Live weight components }(\mathrm{kg})\end{array}$} & \multicolumn{3}{|c|}{$\begin{array}{l}\text { Tratamentos } \\
\text { Treatments }\end{array}$} & \multirow[t]{2}{*}{$\mathrm{CV}$} & \multirow[t]{2}{*}{$\mathrm{F}$} & \multirow[t]{2}{*}{$\operatorname{Pr}>\mathrm{F}$} \\
\hline & $\begin{array}{l}\text { PCA } \\
R p\end{array}$ & $\begin{array}{l}\mathrm{CON} \\
\mathrm{CON}\end{array}$ & $\begin{array}{l}\mathrm{CCF} \\
C C F\end{array}$ & & & \\
\hline $\begin{array}{l}\text { Cabeça } \\
\text { Head }\end{array}$ & 0,999 & 1,013 & 1,070 & 10,13 & 0,78 & 0,4773 \\
\hline $\begin{array}{l}\text { Patas } \\
\text { Legs }\end{array}$ & 0,735 & 0,763 & 0,700 & 5,83 & 3,31 & 0,0644 \\
\hline $\begin{array}{l}\text { Pele } \\
\text { Skin }\end{array}$ & $3,055^{\mathrm{a}}$ & $2,918^{\mathrm{ab}}$ & $2,681^{b}$ & 5,52 & 8,43 & 0,0035 \\
\hline $\begin{array}{l}\text { Sangue } \\
\text { Blood }\end{array}$ & 1,314 & 1,310 & 1,269 & 9,37 & 0,25 & 0,7816 \\
\hline $\begin{array}{l}\text { Pulmão + Traquéia } \\
\text { Lungs-trachea }\end{array}$ & 0,431 & 0,467 & 0,462 & 13,90 & 0,57 & 0,5788 \\
\hline $\begin{array}{l}\text { Coração } \\
\text { Heart }\end{array}$ & 0,142 & 0,135 & 0,123 & 14,73 & 1,46 & 0,2637 \\
\hline $\begin{array}{l}\text { Fígado } \\
\text { Liver }\end{array}$ & 0,442 & 0,418 & 0,424 & 7,72 & 0,87 & 0,4389 \\
\hline $\begin{array}{l}\text { Rins } \\
\text { Kidney }\end{array}$ & 0,087 & 0,088 & 0,080 & 7,34 & 2,57 & 0,1097 \\
\hline $\begin{array}{l}\text { Rúmen+retículo vazio } \\
\text { Rumen + empty reticle }\end{array}$ & 0,399 & 0,415 & 0,477 & 21,94 & 1,14 & 0,3451 \\
\hline $\begin{array}{l}\text { Omaso vazio } \\
\text { Empty omasum }\end{array}$ & 0,041 & 0,052 & 0,055 & 30,59 & 1,30 & 0,3003 \\
\hline $\begin{array}{l}\text { Abomaso vazio } \\
\text { Empty abomasum }\end{array}$ & $0,167^{\mathrm{a}}$ & $0,141^{b}$ & $0,125^{\mathrm{b}}$ & 9,62 & 12,08 & 0,0007 \\
\hline $\begin{array}{l}\text { Conteúdo gástrico } \\
\text { Gastric content }\end{array}$ & $1,401^{b}$ & $2,414^{\mathrm{ab}}$ & $3,147^{\mathrm{a}}$ & 36,28 & 6,50 & 0,0093 \\
\hline $\begin{array}{l}\text { Conteúdo intestinal } \\
\text { Gastrointestinal content }\end{array}$ & 0,975 & 1,000 & 1,231 & 22,93 & 1,98 & 0,1719 \\
\hline
\end{tabular}

Médias seguidas de letras diferentes na linha diferem $(P<0,05)$ pelo teste Tukey.

Averages followed by different letters in line differ $(P<.05)$ by Tukey test.

PCA e semelhança em relação aos animais do CON, ao passo que os animais da PCA não diferiram do CON. Esse aspecto pode ser explicado pela menor velocidade de passagem da silagem de sorgo pelo estômago em relação ao azevém, ocasionando maior peso do conteúdo gástrico. Siqueira et al. (2001), ao confinarem cordeiros cruza Ile de France $x$
Corriedale, não castrados de parto simples e abatidos aos $28 \mathrm{~kg}$, descrevem que o conteúdo gastrintestinal é fator determinante no rendimento da carcaça, pois alimentos diferentes com velocidades de passagem variáveis e períodos de jejum sem padronização podem representar um valor numérico significativo. 
Tabela 4 - Percentuais dos componentes do peso vivo em relação ao peso de abate nos tratamentos (pastagem cultivada de azevém - PCA, confinamento sem alimentação privativa - CON e confinamento com alimentação privativa - CCF) coeficiente de variação $(C V)$, valor de $F(F)$ e probabilidade $(P r>F)$

Table 4 - Percentage of live weight components in relation to the slaughter weight in the treatments (ryegrass pasture - RP, confinement - CON and confinement with creep feeding - CCF, coefficient of variation $(C V), F$ value $(F)$ and probability $(\operatorname{Pr}>\mathrm{F})$

\begin{tabular}{|c|c|c|c|c|c|c|}
\hline \multirow[t]{2}{*}{$\begin{array}{l}\text { Componentes do peso vivo (\%) } \\
\text { Live weight components (\%) }\end{array}$} & \multicolumn{3}{|c|}{$\begin{array}{l}\text { Tratamentos } \\
\text { Treatments }\end{array}$} & \multirow[t]{2}{*}{$\mathrm{CV}$} & \multirow[t]{2}{*}{$\mathrm{F}$} & \multirow[t]{2}{*}{$\operatorname{Pr}>\mathrm{F}$} \\
\hline & $\begin{array}{l}\text { PCA } \\
\text { CON }\end{array}$ & $\begin{array}{l}\mathrm{RP} \\
C C F\end{array}$ & $\begin{array}{l}\mathrm{CON} \\
C C F\end{array}$ & & & \\
\hline $\begin{array}{l}\text { Cabeça } \\
\text { Head }\end{array}$ & 3,61 & 3,64 & 3,89 & 9,33 & 1,80 & 0,3274 \\
\hline $\begin{array}{l}\text { Patas } \\
\text { Legs }\end{array}$ & 2,58 & 2,68 & 2,65 & 5,825 & 0,66 & 0,5317 \\
\hline $\begin{array}{l}\text { Pele } \\
\text { Skin }\end{array}$ & $11,05^{\mathrm{a}}$ & $10,50^{\mathrm{ab}}$ & $9,70^{\mathrm{b}}$ & 6,00 & 6,36 & 0,0100 \\
\hline $\begin{array}{l}\text { Sangue } \\
\text { Blood }\end{array}$ & 4,76 & 4,71 & 4,62 & 9,71 & 0,15 & 0,8611 \\
\hline $\begin{array}{l}\text { Pulmão + Traquéia } \\
\text { Lungs-trachea }\end{array}$ & 1,56 & 1,68 & 1,68 & 14,29 & 0,51 & 0,6090 \\
\hline $\begin{array}{l}\text { Coração } \\
\text { Heart }\end{array}$ & 0,51 & 0,48 & 0,44 & 15,50 & 1,23 & 0,3188 \\
\hline $\begin{array}{l}\text { Fígado } \\
\text { Liver }\end{array}$ & 1,60 & 1,50 & 1,54 & 7,16 & 1,10 & 0,3571 \\
\hline $\begin{array}{l}\text { Rins } \\
\text { Kidney }\end{array}$ & 0,36 & 0,37 & 0,37 & 6,97 & 2,22 & 0,1426 \\
\hline $\begin{array}{l}\text { Rúmen+retículo vazio } \\
\text { Rumen }+ \text { empty reticle }\end{array}$ & 1,44 & 1,49 & 1,74 & 22,42 & 1,21 & 0,3270 \\
\hline $\begin{array}{l}\text { Omaso vazio } \\
\text { Empty omasum }\end{array}$ & 0,15 & 0,18 & 0,20 & 31,02 & 1,30 & 0,3003 \\
\hline $\begin{array}{l}\text { Abomaso vazio } \\
\text { Empty abomasum }\end{array}$ & $0,60^{\mathrm{a}}$ & $0,51^{b}$ & $0,46^{\mathrm{b}}$ & 9,97 & 10,97 & 0,0012 \\
\hline $\begin{array}{l}\text { Conteúdo gástrico } \\
\text { Gastric content }\end{array}$ & $5,09^{\mathrm{b}}$ & $8,72^{\mathrm{ab}}$ & $11,47^{\mathrm{a}}$ & 36,72 & 6,42 & 0,0097 \\
\hline $\begin{array}{l}\text { Conteúdo intestinal } \\
\text { Gastrointestinal content }\end{array}$ & 3,52 & 3,60 & 4,49 & 23,11 & 2,15 & 0,1514 \\
\hline
\end{tabular}

Médias seguidas de letras diferentes na linha diferem $(P<0,05)$ pelo teste Tukey.

Averages followed by different letters in line differ $(P<.05)$ by Tukey test.

\section{Conclusões}

A terminação de cordeiros ao pé da mãe em confinamento a céu aberto com ou sem alimentação privativa, assim como o uso de pastagem cultivada de azevém, é uma alternativa técnicamente viável.

\section{Literatura Citada}

ASSOCIATION OF ANALITIC CHEMIST - AOAC. Official methods of analysis. 14.ed. Washington, D.C.: 1984. 1141p.

ÁVILA, V.S. Crescimento e influência do sexo sobre os componentes do peso vivo em ovinos. Pelotas: Universidade Federal de Pelotas, 1995. 206p. Dissertação (Mestrado em Zootecnia) - Universidade Federal de Pelotas, 1995.

BRASIL- MINISTÉRIO DA AGRICULTURA, Levantamento de Reconhecimento dos Solos do Estado do Rio Grande do Sul. Recife, Ministério da Agricultura, 1973. 430p. (Boletim Técnico).
CAMPBELL, A.G. Grazed pastures parameters: I .Pasture dry matter production and availability in a stocking rate and grazing management experiment with dairy cows. Journal of Agricultural Science, v.67 n.2, p.211-216, 1966

CARNEIRO, R.M. Avaliação do desempenho de cordeiros de parto simples e duplo desmamados e não desmamados, abatidos aos 30 kg. Santa Maria: Universidade Federal de Santa Maria, 2001. 60p. Dissertação (Mestrado em Zootecnia) - Universidade Federal de Santa Maria, 2001.

CARVALHO, S.; PIRES, C.C.; PERES, J.R.R. et al. Desempenho de cordeiros machos inteiros, machos castrados e fêmeas, alimentados em confinamento. Ciência Rural, v.29, n.1, p.129-133, 1999.

FAGUNDES NETO, J.C.; BRAGA, A.P.; BARRA, P.B. et al. Substituição parcial do farelo de soja pela mistura milho/uréia sobre o rendimento de carcaça de ovinos mestiços de Santa Inês In REUNIÃO ANUAL DA SOCIEDADE BRASILEIRA DE ZOOTECNIA, 39., 2002, Recife. Anais... Recife: Sociedade Brasileira de Zootecnia CD ROM. 
FREITAS, E.A.G.; DUFLOTH, J.H.; GREINER, L.C. Tabela de composição químico-bromatológica e energética dos alimentos para ruminantes em Santa Catarina. Florianópolis: EPAGRI. 1994. 333p. (Documentos, 155)

GARDNER, A.L. Técnicas de pesquisa em pastagens e aplicabilidade de resultados em sistemas de produção. Brasília: II CA/EMBRAPA-CNPGL. 1986, 197p. (Série publicações Miscelâneas, 634)

GASTALDI, K.A.; SILVA SOBRINHO, G.A.; GARCIA, C.A. et al. Influência de diferentes relações volumoso: concentrado e pesos de abate de cordeiros confinados. Componentes do peso vivo. In: REUNIÃO ANUAL DA SOCIEDADE BRASILEIRA DE ZOOTECNIA, 37., 2000, Viçosa, MG. Anais... Viçosa, MG: Sociedade Brasileira de Zootecnia, 2000. p.653-656.

GIBB, M.J.; TREACHER, T.T. The effect of herbage allowance on lambs graazing perennial ryegrass and red clover swards. Journal of Agricultural Science, v.86, p.355-365, 1976.

KEMPSTER, A.J.; CROSTON, D.; GUY, D.R. et al. Growth and carcass characteristics of crossbred lambs by tem sire breds, compared at the same estimated carcass subbcutaneous fat proportion. Animal Production, v.44, p.99-106, 1987.

MONTEIRO, E.M. Influência do cruzamento Ile de France $x$ Corriedale (F1) nos parâmetros de qualidade da carne de cordeiro. São Paulo: Universidade de São Paulo, 1998. 99p. Tese (Doutorado em Ciência dos Alimentos) Universidade de São Paulo, 1998.

MORENO, J.A. Clima do Rio Grande do Sul. Porto Alegre: Secretaria da Agricultura, 1961.41p.

MÜLLER, L. Normas para avaliação de carcaças e concurso de carcaças de novilhos. Santa Maria: Universidade Federal de Santa Maria, 1980. v.1, 31p.

MÜLLER, L; PIRES, C.C.; TONETTO, C.J. et al. Proporção dos componentes do peso vivo de cordeiros submetidos a três sistemas de terminação. In: REUNIÃO ANUAL DA SOCIEDADE BRASILEIRA DE ZOOTECNIA, 39., 2002, Recife. Anais... Recife: Sociedade Brasileira de Zootecnia CD ROM. OSÓRIO, J.C.S.; OSÓRIO, M.T.; OLIVEIRA, N.M. Produção de carne na raça Ideal. Pelotas: Universidade Federal de Pelotas, 1997. 57p.
OSÓRIO, J.C.S.; OLIVEIRA, N.M.; OSÓRIO, M.T. et al. Produção de carne em cordeiros cruza Border Leicester com ovelhas Corriedale e Ideal. Revista Brasileira de Zootecnia, v.31, n.3, p.1469-1480, 2002 (suplemento).

ROQUE, A.P.; OSÓRIO, J.C.S.; JARDIM, P.O. et al. Desenvolvimento relativo dos componentes do peso vivo em cordeiros de cinco raças. In: REUNIÃO ANUAL DA SOCIEDADE BRASILEIRA DE ZOOTECNIA, 35., 1998, Botucatu. Anais...Botucatu: Sociedade Brasileira de Zootecnia, 1998. p.624-626.

STATISTICAL ANALYSES SYSTEM - SAS. User's guide: statistics. version 6.8. Cary: 1993. 956p.

SAINZ, R.D. Qualidade das carcaças e da carne ovina e caprina. In: REUNIÃO ANUAL DA SOCIEDADE BRASILEIRA DE ZOOTECNIA, 33., 1996, Fortaleza. Anais... Fortaleza: Sociedade Brasileira de Zootecnia, 1996. p.3-14.

SILVA SOBRINHO, A.G.; BATISTA, A.M.; SIQUEIRA, ER. et al. Nutrição de ovinos. Jaboticabal: FUNEP, 1996. 258p.

SIQUEIRA, E.R.; SIMÕES, C.D.; FERNANDES, S. et al. Efeito do sexo e do peso ao abate sobre a produção de carne de cordeiros. Morfometria da carcaça, peso dos cortes, composição tecidual e componentes não constituintes da carcaça. Revista Brasileira de Zootecnia, v.30, n.4, p.1299-1307, 2001.

TONETTO, C.; PIRES, C.C.; MULLER, L. et al. Rendimentos de cortes da carcaça, características da carne e componentes do peso vivo em cordeiros terminados em três sistemas de alimentação. Revista Brasileira Zootecnia, v.33, n.1, p.234-241, 2004.

TILLEY, J.M.; TERRY, R.A. A two-estage technique for the in vitro digestion of forage crops. Journal British Grassland Society, v.18, p.104-111, 1963. 